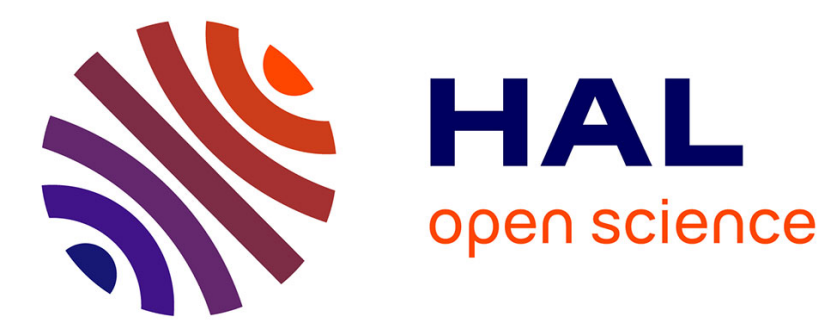

\title{
Scale effects on the response of composite structures under impact loading
}

Philippe Viot, Ludovic Ballère, Laurent Guillaumat, Jean-Luc Lataillade

\section{To cite this version:}

Philippe Viot, Ludovic Ballère, Laurent Guillaumat, Jean-Luc Lataillade. Scale effects on the response of composite structures under impact loading. Engineering Fracture Mechanics, 2008, 75 (9), pp.27252736. 10.1016/j.engfracmech.2007.03.001 . hal-01011272

\section{HAL Id: hal-01011272 https://hal.science/hal-01011272}

Submitted on 23 Jun 2014

HAL is a multi-disciplinary open access archive for the deposit and dissemination of scientific research documents, whether they are published or not. The documents may come from teaching and research institutions in France or abroad, or from public or private research centers.
L'archive ouverte pluridisciplinaire HAL, est destinée au dépôt et à la diffusion de documents scientifiques de niveau recherche, publiés ou non, émanant des établissements d'enseignement et de recherche français ou étrangers, des laboratoires publics ou privés. 


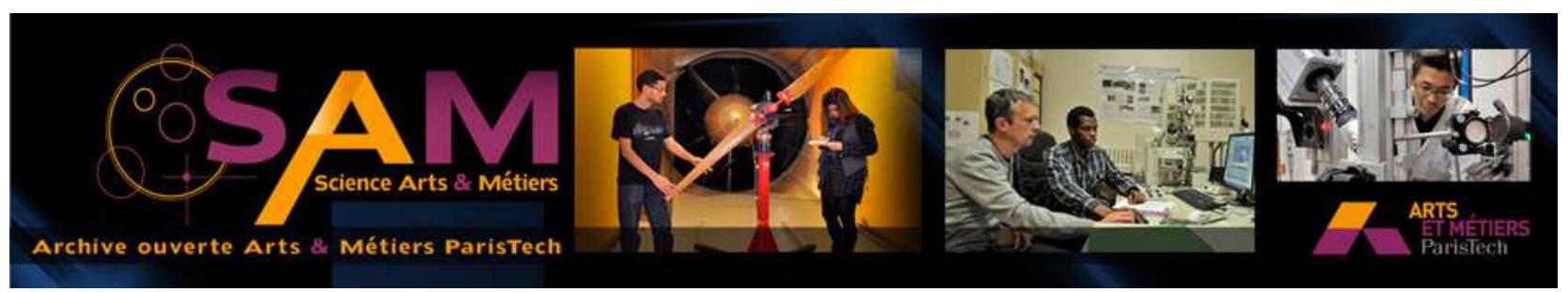

Science Arts \& Métiers (SAM)

is an open access repository that collects the work of Arts et Métiers ParisTech researchers and makes it freely available over the web where possible.

This is an author-deposited version published in: http://sam.ensam.eu

Handle ID: .http://hdl.handle.net/10985/8294

\section{To cite this version :}

Philippe VIOT, Ludovic BALLÈRE, Laurent GUILLAUMAT, Jean-Luc LATAILLADE - Scale effects on the response of composite structures under impact loading - Engineering Fracture Mechanics Vol. 75, n9, p.2725-2736 - 2008 


\title{
Scale effects on the response of composite structures under impact loading
}

\author{
Philippe Viot *, Ludovic Ballère, Laurent Guillaumat, Jean-Luc Lataillade \\ LAMEFIP Laboratory, ENSAM de Bordeaux, Esplanade des Arts et Métiers, 33405 Talence Cedex, France
}

\begin{abstract}
For several years, composite materials have taken a significant part in the realization of structures designed for transport (aeronautical, nautical, automotive...). In order to qualify the behavior of such structures, preliminary validation tests have to be done. These specific tests are often very expensive and difficult to set up, especially when the structure dimensions are large (fuselages of aircraft, ship hulls...). An alternative way is then to employ small-scale models.

The use of these reduced scale structures requires the identification of similitude models allowing the extrapolation of the small-scale model behavior to the real structure. Although largely developed in the case of homogeneous materials, such similitude techniques are not clearly identified for composite materials taking into account the damage evolution during an impact.

The purpose of this article is firstly to present existing similitude techniques making it possible to predict the composite structure behaviour from the knowledge of small-scale model response. Secondly, experiments were done on two scale of samples carried out by stratification of unidirectional carbon/epoxy plies. These results were finally compared with the analytical predictions of similitude laws currently used.

The aim of this paper is to contribute to similitude laws development applied to composite structures. These laws permit to extrapolate the small-scale model behavior to the real scale one. Existing approaches have been established following two different methods. They are summarized in this paper and applied to impact loadings on two laminated plate scales. In order to complete data collected by "conventional" instrumentation (force transducer, displacement sensor, accelerometer. .), optical device such as an high-velocity CCD camera, associated with optical techniques for the monitoring of markers, were used. These techniques make possible to compare displacement lines corresponding to each scale. It is shown that existing similitude laws, used for elastic materials, do not allow to simulate the behavior of the real scale when this one is damaged.
\end{abstract}

Keywords: Similitude laws; Impact; Composite materials; Damage

\footnotetext{
* Corresponding author.

E-mail address: philippe.viot@lamef.bordeaux.ensam.fr (P. Viot).
} 


\section{Introduction}

In a great number of scientific and technical fields (fluid mechanics, aerodynamics, civil engineering), for the study of complex or large-sized structures (study of avalanche in a valley, streamline flow in a whole of buildings...), it is sometimes impossible - or too expensive - to study the behavior of the real structure in its environment, and if the numerical approach does not allow to build a numerical model - or virtual model -, it is then necessary to define a small-scale model, accurate reproduction of the real structure. In this case, it is essential to establish parameters which govern the reliability - or similitude - of the model with respect to the structure. In the fields, which - for a long time - use small-scale models to estimate the behavior of the real scale prototype - for example, Reynolds or Froude numbers in fluid mechanics -, similitude laws between model and prototype are well-known and give pertinent results. In the field which interests us more particularly, i.e. the impact effects on composite structures, it is relatively new to use these methods and the experiments carried out on the model, coupled with the suggested similitude laws, generally do not allow to describe classical damage phenomena of the composite structure at the real scale.

However, composite materials are more and more used in large-sized parts, which must often ensure severe mechanical functions (fuselage of aircraft, hull or mast of ship...). During the manufacturing of these structures, their storage and especially their use, they can be damaged by impact (tool shock, machine element projection...) and these dynamic loading does not imply a damage visible with the naked eye. And if it is visible at the surface of the composite part (because one can observe indentation, delamination or fiber rupture) and if complementary measurement allows to confirm the damage, its nature and its size, it is necessary to estimate the residual behavior in service of the part or to evaluate if the mechanical characteristics are degraded. Thus, since it is not possible to avoid the damage in the structure lifetime, it is essential to appreciate its criticality. The experimental study of the structure behavior after impact can be very expensive - or impossible - for large-sized parts. Hence, scale models can be used to appreciate the residual performances of the real structure. This methodology then requires the use - or the development - of similitude laws making it possible to predict the real structure behavior from the results obtained with the models. The aim of this article is to present the experimental study undertaken on two scales of laminated plane plates stressed in bending by impact. These experimental results are compared with the results of similitude law results mainly used in the case of composite structures.

\section{Similitude laws}

Two basic approaches are used to develop scaling rules (see Abrate [1]). The first one is based on a dimensional analysis using Buckingham's Pi theorem [2]. The second one starts with the dynamic equations of the system (see Refs. [3,4]).

Morton [5] studied scale effects, using a dimensional analysis, in the case of beams subjected to impact loading. For homogeneous isotropic beams, considering a non damaged behavior, it is possible to identify thirteen influential parameters in order to completely model the test : the beam geometrical parameters (length $l$, thickness $h$ and width $b$ ), the beam mechanical properties (Young's modulus $E$ and Poisson's ratio $v$ ), the impactor features (Poisson's ratio $v_{i}$, Young modulus $E_{i}$, volumic mass $\rho_{i}$, the radius $R_{i}$ and the impact velocity $V_{i}$ ), the central deflection of the sample $w$ and time $t$.

Using Buckingham's Pi theorem [2], 10 nondimensional parameters can be formed (Table 1).

If the prototype is a true replica of the model and if the same materials are used, then all the geometrical terms are equal between the prototype and the model. Equalizing all these terms, the impactor velocity has to

Table 1

Nondimensional parameters

\begin{tabular}{|c|c|c|c|c|}
\hline Geometrical parameters & $\Pi_{1}=\frac{w}{h}$ & $\Pi_{2}=\frac{l}{h}$ & $\Pi_{3}=\frac{b}{h}$ & $\Pi_{4}=\frac{R_{i}}{h}$ \\
\hline Materials parameters & $\Pi_{5}=\frac{E_{i}}{E}$ & $\Pi_{6}=v$ & $\Pi_{7}=v_{i}$ & $\Pi_{8}=\frac{\rho_{i}}{\rho}$ \\
\hline Tests conditions & $\Pi_{9}=\frac{\rho_{i} V_{i}^{2}}{E}$ & $\Pi_{10}=\frac{t V_{i}}{h}$ & - & - \\
\hline
\end{tabular}


remain the same. The $\Pi_{10}$ term implies that the time have to be scaled. Finally, considering the scale factor between the model and the real structure $\lambda$, impact energy is scaled by $\lambda^{3}$ and the impact force by $\lambda^{2}$.

Nettles et al. [6] used this method in order to study quasi-static indentation and impact of unidirectional composite plates. Experimental results were compared to parameters obtained by similitude laws (contact force, displacement, damage area and indentation). Differences are significant.

Dormegnie [7] observe the same conclusions in the case of laminated omega-shaped structures subjected to crash.

The second approach we can find in the literature is based on the dynamic theorem and was particularly developed by Qian and Swanson [3,4] for plates. Experiments were realized on composite plates considering scale factors $\lambda$ of 1,3 and 5. Deflection and contact force results exhibit good accuracy of these laws. Nevertheless, it is more difficult to predict damage size.

Many authors have established similtude laws applied to composite structures based on this approach. For instance, Ungbhakorn and Singhatanadgid or Razaeepazhand and Simitses have used it to study cylindrical shells buckling under axial loading [8,9]. A similar investigation was presented by Chouchaoui et al. for various loadings [10].

Simitses and Rezaeepazhand adopted a similar approach to develop laws for laminated plates subjected to quasi-static bending [11] and for vibration response of cylindrical shells [12].

It is interesting to note that, contrary to Qian and Swanson's first study, these authors assign a scale factor to the structure materials properties.

To conclude, described methods allow us to establish relationships between two scales. Therefore, in the case of laminate plates subjected to impact, all plate dimensions as well as the impactor radius and the deflection are scaled by $\lambda$. Concerning materials specific characteristics and impact velocity, they remain the same between the model and the prototype. Time is scaled by $\lambda . \lambda^{3}$ Assigned to impact mass implies that energy is scaled too by $\lambda^{3}$. Finally, contact forces are scaled by $\lambda^{2}$.

\section{Experimental methods}

\subsection{Drop tower apparatus}

The drop tower consists of two rectified metal columns fixed on a metallic gantry (Fig. 1). These two columns allow to ensure the guidance of a falling weight or impactor. A winch (by the way of an electromagnet stuck on the impactor) makes it possible to rise the falling weight ( $25 \mathrm{~kg}$ maximum mass) to the desired height of impact (2.8 m maximum). The sample or the structure to be tested is fixed under the impactor and on a seismic flagstone (constituted of reinforced concrete block). During the test, the impactor is released by the electromagnet and freefalls guided by the two columns. It comes to strike the structure to be tested. An anti-bouncing device is implemented to avoid a second shock which, even if it is of lower amplitude, could damage a little more the structure. Without this device, it would be difficult to determine the effect of the shock

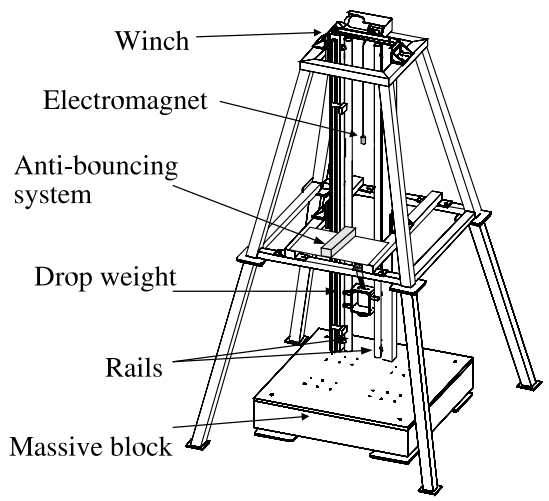

Fig. 1. Drop tower scheme. 
on the structure after the test. Indeed, the postmortem analysis would be disrupted by the eventual damage caused by successive rebounds. This experimental device is instrumented with a set of sensors which allow to measure the various test parameters (displacement, force, acceleration...). A first laser sensor (sensor 1) (50 $\mathrm{mm}$ effective range) measures the impactor displacement during its fall, the impact phase and the rebound (Fig. 2). It also allows, by derivation, to determine the evolution of the impactor velocity. One thus checks the impact velocity (theoretical velocity being given by the formula $V_{\text {init }}=\sqrt{2 \cdot g \cdot h}$ with $g$ the gravitational acceleration and $h$ the drop height). A second laser sensor (of lower effective range but better accuracy, sensor 2 ) is used to measure the displacement of a structure point. Generally placed under the impact point, its measurement, compared with the laser sensor 1 results, indicates if the impactor remains in contact with the structure during the test. A piezoelectric force sensor, fixed on the impactor, allows to obtain the contact force between the impactor and the structure. By integration, the measurement of a piezoelectric accelerometer allows to calculate the projectile velocity and to validate the datas obtained with the laser sensor 1.

This measurement equipment is supplemented by an high-speed video device. A camera CCD Phantom V4 films the test to visualize the effect of the impact on the structure during the stress. It also allows to measure structure point displacements by the way of marker tracking technique or deformation field from digital image correlation technique. For these tests, the recording frequency was 2500 frames per second.

\subsection{Material}

Two different scales of plane plates were manufactured. Specimens were made using unidirectional carbon/ epoxy pre-preg 914C-TS(6K)-5-34\% and the ply thickness is about $125 \mu \mathrm{m}$. First sample (sample A) characteristics were chosen in order to obtain symmetrical stacking. Therefore, the stacking sequence for sample $\mathrm{A}$ is :

$$
\left(0^{\circ}\right)_{2}\left(90^{\circ}\right)_{3}\left(0^{\circ}\right)_{2}\left(90^{\circ}\right)_{3}\left(0^{\circ}\right)_{2}
$$

After the first stage of plies stacking, samples have been cured one hour at $175^{\circ} \mathrm{C}$ and 7 bar pressure, plus $4 \mathrm{~h}$ postcure at $190{ }^{\circ} \mathrm{C}$. Twelve hours later, they were cut out with the following dimensions: length $=100 \mathrm{~mm}$, width $=50 \mathrm{~mm}$. The final thickness of sample A is $1.5 \mathrm{~mm}$ (see Fig. 3).

The second scale characteristics were determined using similitude laws previously described with a scale factor $\lambda=2$. Sample thickness (of $3 \mathrm{~mm}$ ), controlled by the stacking sequence, was obtained by doubling each ply thickness ("Sub-Ply Level Scaling" method proposed by Jackson [13]). So the stacking sequence is for the sample B:

$$
\left(0^{\circ}\right)_{4}\left(90^{\circ}\right)_{6}\left(0^{\circ}\right)_{4}\left(90^{\circ}\right)_{6}\left(0^{\circ}\right)_{4}
$$

The manufacturing process characteristics (temperature, pressure and duration) for these sample B are identical to the sample A.

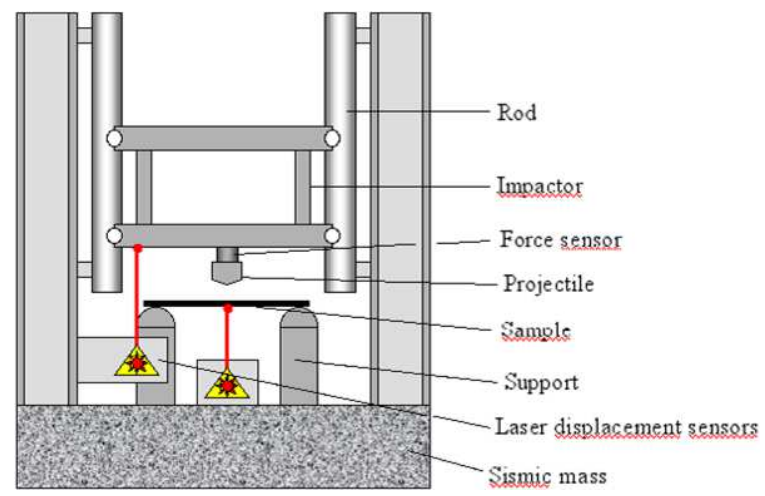

Fig. 2. Impact device. 


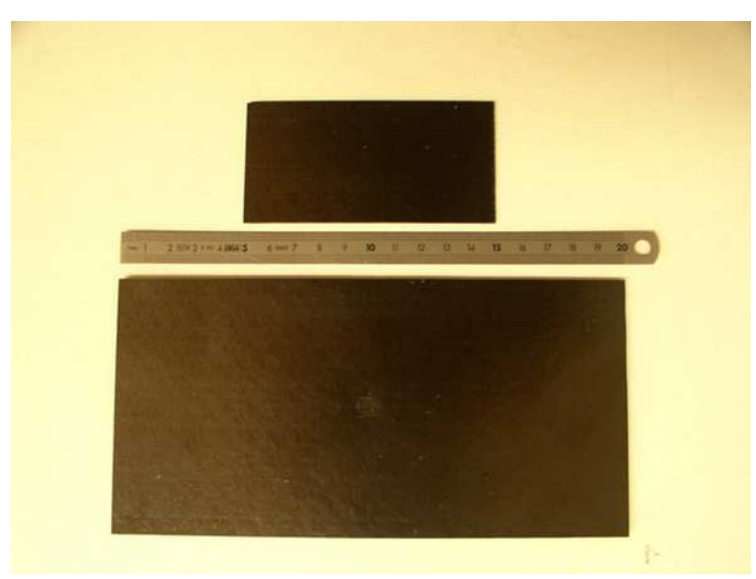

Fig. 3. Composite samples A and B.

\section{Results}

\subsection{Test conditions}

Impact tests were carried out by imposing two different projectile velocities ( $V_{\text {init }}=1.8 \mathrm{~m} \mathrm{~s}^{-1}$ and $2.2 \mathrm{~m} \mathrm{~s}^{-1}$ ) in order to estimate the performances of the similitude laws to describe the behavior of a laminated composite structure at various scales. The lowest velocity was determined to reach high impact energy without generating damage visible with the naked eye. The velocity of $2.2 \mathrm{~m} \mathrm{~s}^{-1}$ was designed to reach a significant damage on at least one of the two scales. It was thus possible to measure firstly the structure response according to their damage rate and secondly to estimate the relevance of the similitude laws in both cases (without or with damage).

The composite plates are placed on two simple supports to obtain a dynamic test of "three points bending". The distance between supports was given according to plate dimensions and the conditions imposed by the similitude laws. The distance $d$ between supports is $100 \mathrm{~mm}$ for sample A, it is by consequence $\lambda d$ (i.e. $200 \mathrm{~mm}$ with $\lambda=2$ ) for the sample B.

Concerning the other parameters of these tests, they were also determined by the similitude laws (see Table 2); the impactor diameter for the samples $\mathrm{A}$ and $\mathrm{B}$ is scaled by $\lambda$, the impactor of the sample $\mathrm{B}$ is thus twice larger. The mass of the dropping weights depends on $\lambda^{3}$, it is thus $8.6 \mathrm{~kg}$ for the sample $\mathrm{B}$, so eight times the mass of the projectile impacting sample A.

\subsection{Experimental results}

For each test velocity, several samples of each scale (A and B) were tested. It was checked a good reproducibility of the force and displacement results. Figs. 4 and 5 present the pictures extracted from the films carried out during the impacts on the samples $\mathrm{A}$ and $\mathrm{B}$ at a velocity $V_{\text {init }}=2.2 \mathrm{~m} \mathrm{~s}^{-1}$. The similitude laws were particularly well respected since it is difficult to distinguish sample A from sample B on these frames.

Table 2

Test conditions

\begin{tabular}{lll}
\hline & Sample A & Sample B \\
\hline Dropping weight mass $(\mathrm{kg})$ & 1.075 & 8.6 \\
Impact velocities $\left(\mathrm{m} \mathrm{s}^{-1}\right)$ & 1.8 and 2.2 & 1.8 and 2.2 \\
Impactor diameter $(\mathrm{mm})$ & 10 & 20 \\
Boundary conditions & Simple supports & Simple supports \\
Distance $d$ between supports $(\mathrm{mm})$ & 100 & 200 \\
\hline
\end{tabular}



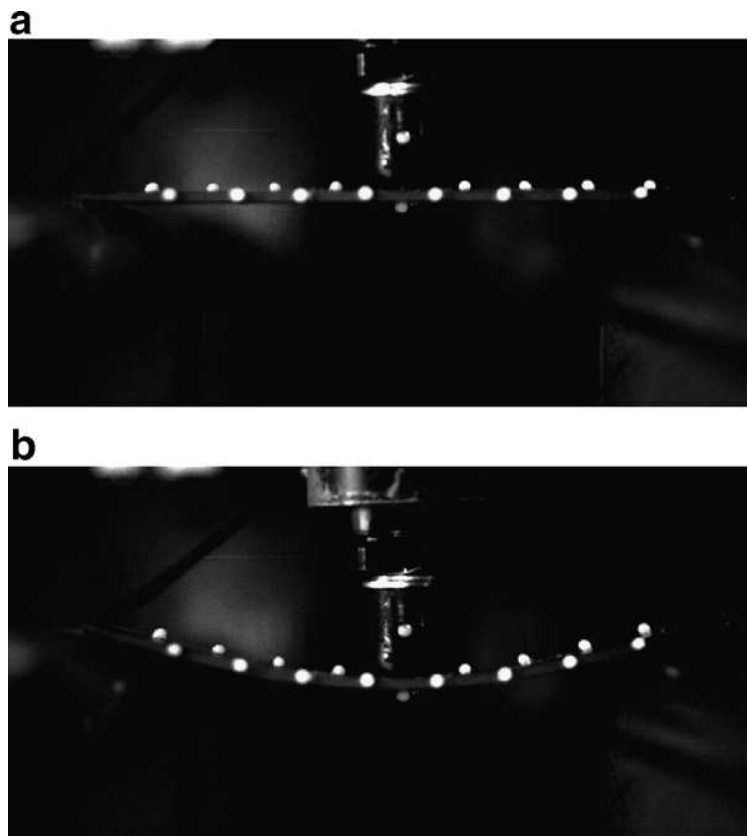

Fig. 4. Impact of sample A at $V_{\text {init }}=2.2 \mathrm{~m} \mathrm{~s}^{-1}$. (a) Just before the contact and (b) at the maximum deformation.
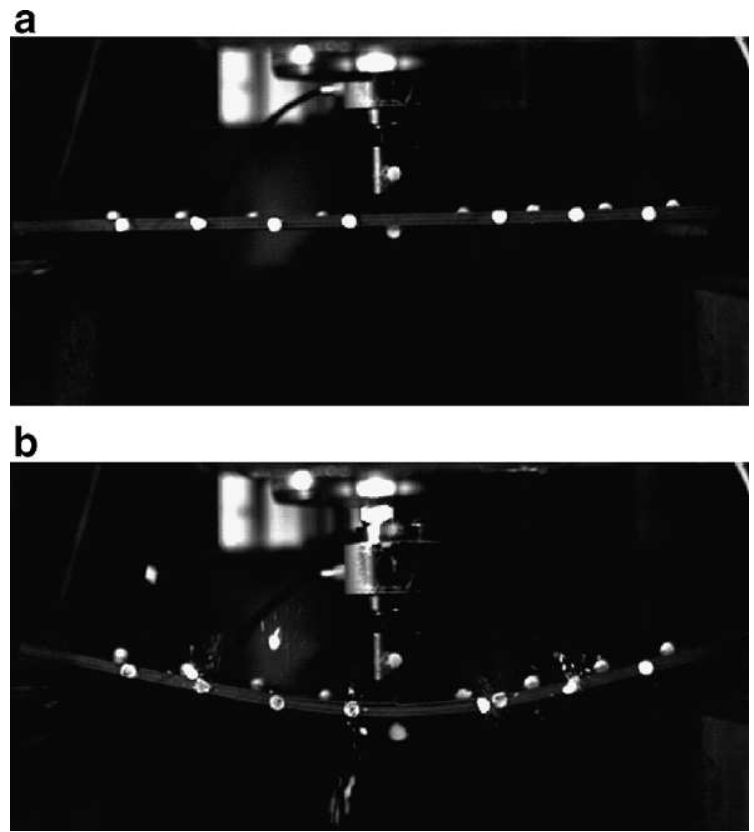

Fig. 5. Impact of sample B at $V_{\text {init }}=2.2 \mathrm{~m} \mathrm{~s}^{-1}$. (a) Just before the contact and (b) at the maximum deformation.

Figures (a) show the impactor position just before the contact and figures (b) reveal the maximum deformation of the tested structure whereas the dropping weight velocity is null. White spheres were stuck on the section and the median plane of the composite plate for better appreciating its deformations visually and measuring, by the technique of markers tracking, the displacement of these points. It was thus possible to calculate the shape of the composite plate deformation at several moments of the impact. The complete results of these measurements will not be presented in this article (see Ref. [14]) but these figures however make it possible to 
show the difference between the behavior of the two plates. On Fig. 5b, one shows the brutal damage of the composite plate B. It is possible to appreciate the delamination which appears along the section of the sample. This damage creates a shock wave (visible also on the force curves) which involves even a separation of the markers of optical measurement. On sample A, at the same impact velocity, this phenomenon does not appear and the damage, if there exists, is not propagated on the whole sample.

These films allow to estimate the different behavior for each impact velocity and on each sample A and B. On the other hand, the sensors of force and displacement make it possible to quantify the response of the composite plates. The first compared results present the evolution of displacement in function of time for the two impact velocities, for sample A (Fig. 6) and for the sample B (Fig. 7). The curves in parabola include three zones: the first test step $[\mathrm{IJ}]$ corresponds to the measurement of the impactor displacement before impact. The slope of this segment allows to control the impact displacement rate. Measured velocities are $V_{1}=1.8 \mathrm{~m} \mathrm{~s}^{-1}$ (test 1) and $V_{2}=2.2 \mathrm{~m} \mathrm{~s}^{-1}$ (test 2). Preliminary tests made it possible to adjust the height of the dropping weight in order to really obtain desired velocities (the theoretical velocity deduced from the formula $V_{\text {init }}=\sqrt{2 \cdot g \cdot h}$ does not take into account the friction between dropping weight and its guide columns).

$[\mathrm{JK}]$ is the impact phase of the test. One can thus estimate the contact duration (length $\mathrm{JK}$ ) and the deflection of the deformed plate (at the point $\mathrm{M}$ ). For sample A tested at the two velocities, the contact duration is

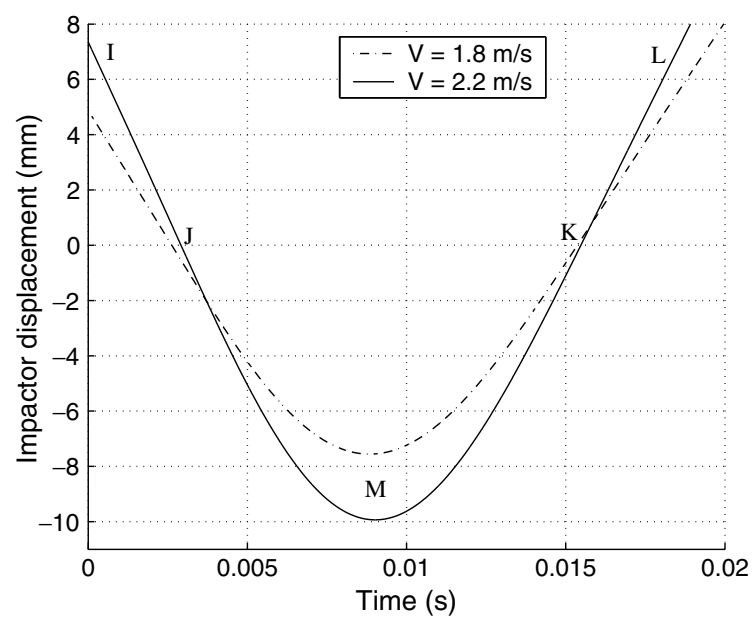

Fig. 6. Displacement evolution as a function of time for sample A.

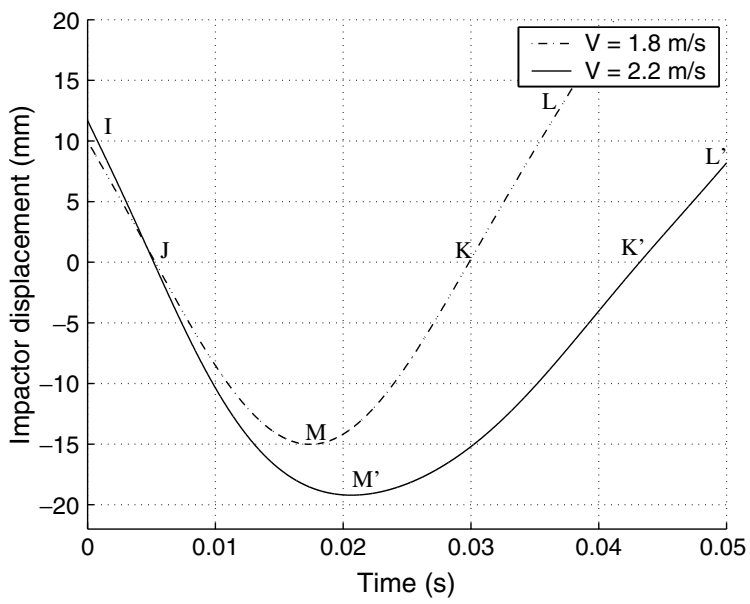

Fig. 7. Displacement evolution as a function of time for sample B. 
quite identical and $\left(t_{\text {contact }}=12 \mathrm{~ms}\right)$. The velocity difference between the two tests does not influence, in a consequent way, the contact duration. Moreover, for test $2\left(V=2.2 \mathrm{~m} \mathrm{~s}^{-1}\right)$ whose kinetic energy of the impactor is most significant, the structure deflection is evidently higher. The measured displacement of the impactor (after contact) for this test is $9.9 \mathrm{~mm}$, and only $7.5 \mathrm{~mm}$ for test 1 at lower velocity. Concerning the sample $\mathrm{B}$, one can note a significant variation of contact durations between the two tests. The contact duration is $24.5 \mathrm{~ms}$ for test 1 , it reaches up to $37 \mathrm{~ms}$ for the test 2 during which one observes a strong damage of the structure. The delamination reduces the sample stiffness and, consequently a sudden reduction of the load occurs. The consequence is an increase in the contact duration. Deflections measured during tests 1 and 2 on these sample B are respectively 15 and $19.2 \mathrm{~mm}$.

The impact test finishes at point $\mathrm{K}$. The dropping weight rises along the guide columns, its velocity is then given by the slope of segment [KL].

The force results of these tests are presented as a function of the impactor displacement (Figs. 8 and 9). For all the tests carried out on sample A, strong oscillations on the force can be observed during the composite structure loading. These load variations are due to the vibration modes generated at the impact time (point $\mathrm{J})$. After the point $\mathrm{M}$ of maximum deformation, these oscillations strongly attenuate. These force-displacement curves being similar, show that the structure stiffness does not depend on the impact velocity.

Only maximum measured force increases according to the test velocity what seems obvious since the impact energy is higher. Lastly, the loading - unloading cycle are very closed which signifies that the damage of the composite plate is reduced and unsignificant.

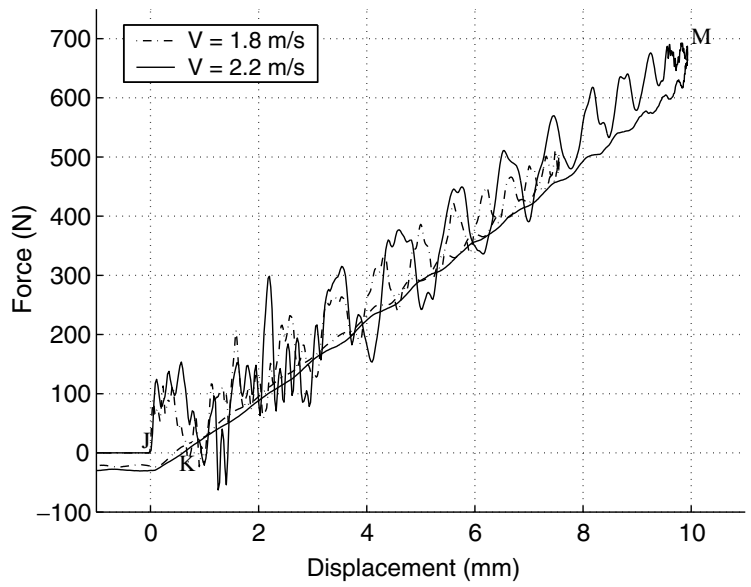

Fig. 8. Force evolution as a function of impactor displacement (sample A).

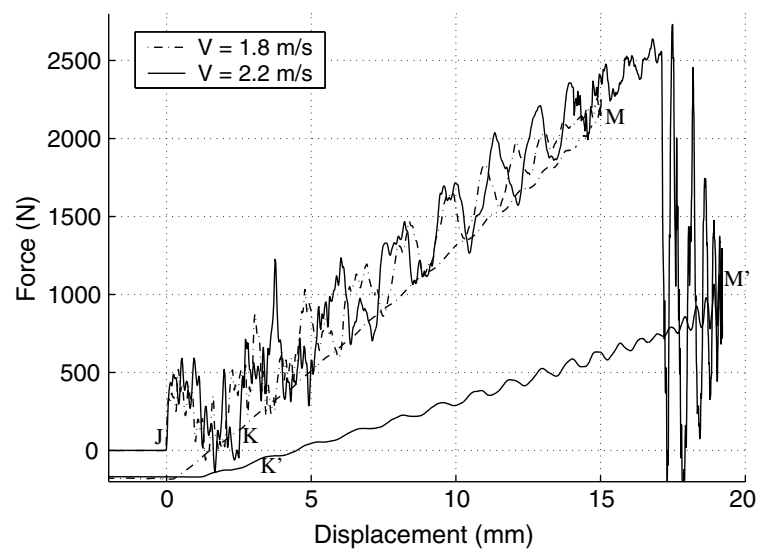

Fig. 9. Force evolution as a function of impactor displacement (sample B). 
As regards the sample $\mathrm{B}$, results are clearly different. If for test 1 (at velocity $V_{1}$ ), the same remarks can be done concerning the loading - unloading cycle (the measured maximum force is then $2265 \mathrm{~N}$ ), test 2 (at higher velocity $V_{2}$ ) shows a partial failure of the composite plate. At this velocity $V_{2}$, the force increases linearly as a function of impact point displacement, exceeds the measured force value for the lower velocity test and reaches the maximum value of $2730 \mathrm{~N}$. Then, a brutal delamination is initiated in the impact point and generates a strong fall of the contact force. In spite of the strong vibrations generated by this phenomenon, the effort supported by the structure can be estimated of $1000 \mathrm{~N}$. The failure phenomenon by composite structure delamination is well highlighted with this test.

Tests were carried out on two scales of composite structure (ratio between the two scales $\lambda=2$ ) and at two impact velocities. At the velocity $V_{1}$ of $1.8 \mathrm{~m} \mathrm{~s}^{-1}$, neither on the samples impacted, nor on the curves results, it could be detected a local damage of the structure. On the contrary, for an higher velocity $V_{2}$ (and thus for an higher impact energy), a significant damage of the large-sized plate B can be observed. This phenomenon has not been noted on sample A loaded at the same impact velocity. In order to study the validity of the similitude laws presented in this article, it is possible to evaluate the response of the sample B (large size) to an impact starting from the results obtained on sample A (small size) and the similitude rules.

\subsection{Similitude law results/experimental results confrontation}

Presented similitude laws show an evolution of the parameters measured during the test according to the scale factor $\lambda^{i}$. Thus, the contact duration of the impactor with the structure and the measured deflection are scaled by $\lambda$ and the force varies in $\lambda^{2}$ during the scaling.

It thus seems interesting to compare these parameters time $t$, displacement $d$ and force $F$ obtained on sample A and scaled by the scale factor $\lambda^{i}$ (with $i \in[1,2]$ ) to those obtained in experiments on the sample $\mathrm{B}$. This study is carried out for two test velocities in order to estimate the relevance of these similitude laws. The first described comparisons concerns the tests carried out at the velocity of $1.8 \mathrm{~m} \mathrm{~s}^{-1}$. During these tests, no damage was noted on the two scales and the structure behavior seems to be elastic; it is thus possible to evaluate the performances of the similitude laws to describe the elastic response of a dynamically loaded composite structure.

The influence of the coefficient $\lambda^{1}$ over displacement $d$ and time $t$ is represented on Fig. 10. The curve $\lambda^{1} A$ deduced from the similitude laws is close to the test result of sample B. The calculated maximum displacement $\lambda^{1} d_{\max }$ (of $15 \mathrm{~mm}$ ) is almost identical to that obtained by test on the sample B. The error can be considered negligible. The calculated contact duration $\lambda^{1} t$ of $24 \mathrm{~ms}$ is slightly higher than the contact duration between the impactor and the sample B. The error between the two values is $2 \%$. For this same impact velocity, the

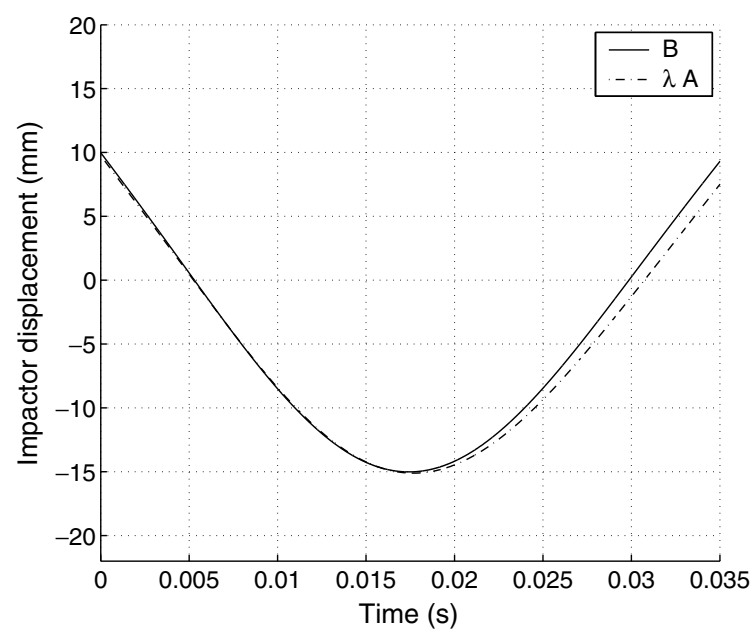

Fig. 10. Comparison between measured impactor displacement and similitude law result (vs time) at $V_{\text {init }}=1.8 \mathrm{~m} \mathrm{~s}^{-1}$. 


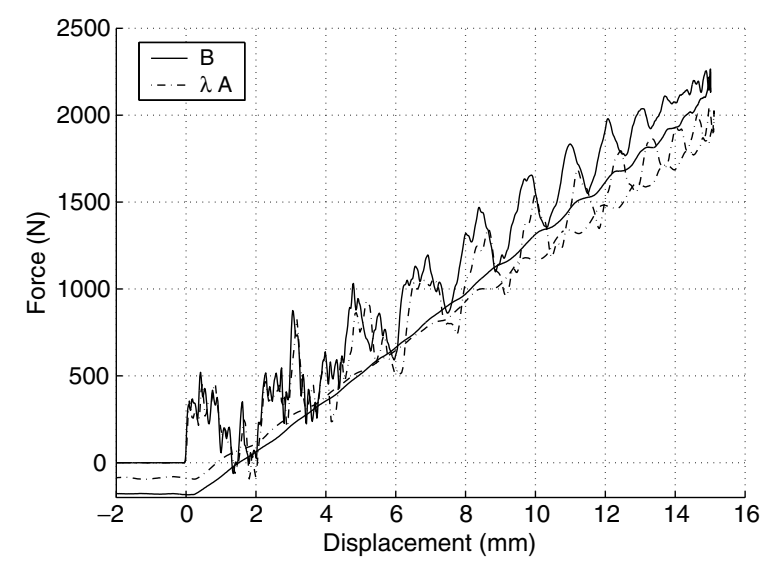

Fig. 11. Comparison between measured force and similitude law result (vs time) at $V_{\text {init }}=1.8 \mathrm{~m} \mathrm{~s}^{-1}$.

force deduced from the results on sample $\mathrm{A}$ and scaled by the coefficient $\lambda^{2}$ is confronted with the force results of the sample B (Fig. 11). If the evolution of the two curves are relatively close, the calculated force $\lambda^{2} F$ does not allow to estimate the real force. $\lambda^{2} F$ is quite lower: the calculated maximum force $\lambda^{2} F_{\max }(2048 \mathrm{~N})$ is $9.6 \%$ lower than the real force.

To conclude, for an impact velocity $V_{1}$, which does not generate a perceptible damage of the sample, the composite structure behavior being elastic, the similitude law assumptions are verified. In the one hand, it appears that these laws allow to describe, with a good accuracy, the maximum deflection of the plate (complementary tests showed that the complete deformation of the plate can be correctly found, see Ref. [14]). The error over the contact duration is also relatively small. On the other hand, the force results are rather disappointing. The difference between the model and the real response reaches up to $9.6 \%$ for a small-scale factor $\lambda$. One wonders whether the capabilities of these laws to predict force results in the case of a higher scale factor, near to those used in industry. It is also necessary to evaluate if these similitude laws can be used on all the elastic range of the structure behavior and if, in particular, it is possible to extend the range of use of these laws to the limit of the material damage behavior. It is mainly for this reason that the tests at the velocity $V_{2}$ were carried out.

The Fig. 12 presents the evolution of the deflection vs. time (these two parameters being scaled by the scale factor $\lambda^{1}$ ). In the first part of the impacts (between points $\mathbf{J}$ and $\mathbf{M}$ ) the two curves are very close. The composite plates on the two scales are not damaged by the impact and the similitude laws can still be validated. The calculated maximum deflection (point $\mathbf{M}$ ) is slightly higher than the one obtained on scale 2 . The error between the two results is only $3 \%$, it is equivalent to the one obtained during the tests at the velocity $V_{1}$. Moreover, on the sample B, the damage by delamination of the composite structure appears a little bit before the point $\mathrm{M}^{\prime}$ (close to time $t=15 \mathrm{~ms}$, value confirmed on the curves force vs time). The sample $\mathrm{B}$ becomes a new structure, less rigid and including a local defect. Presented similitude laws, due to their intrinsic elaboration, cannot predict this evolution. That is why, during the sample unloading (between the points $\mathrm{M}$ and $\mathrm{K}$ or $\mathrm{M}^{\prime}$ and $\mathrm{K}^{\prime}$ ) and the impactor rising, with contact loss, the deduced curve $\lambda^{1} A$ is very far away from the real result. The calculated contact duration (distance $\mathrm{JK}$ ) is of $24 \mathrm{~ms}$, value smaller than the measured value of $37 \mathrm{~ms}$. Concerning the displacement evolution, simulation $\lambda^{1} A$ predicts a contact loss of the impactor with the plate at $t=24 \mathrm{~ms}$ (at the point $\mathrm{K}$ ). Actually, at this moment, the structure deflection (and thus the impactor position) are still of $15 \mathrm{~mm}$. The similitude laws thus do not allow to evaluate the deformation of the composite plate after damage. The same remark for the impactor velocity after the contact loss can be done. The slope of segment [KL] of the curve $\lambda^{1} A$, making it possible the calculation of the impactor velocity, is clearly higher than the real speed deduced from the part of curve $\left[\mathrm{K}^{\prime} \mathrm{L}^{\prime}\right]$. Indeed, the post impact velocity of the dropping weight depends on the structure stiffness. The same remarks can be made on the evolution of the force scaled by the coefficient $\lambda^{2}$ (Fig. 13). For values smaller than the delamination load of the structure B, the forces estimated by the similitude laws are close to those really measured. Passed this damage threshold, 


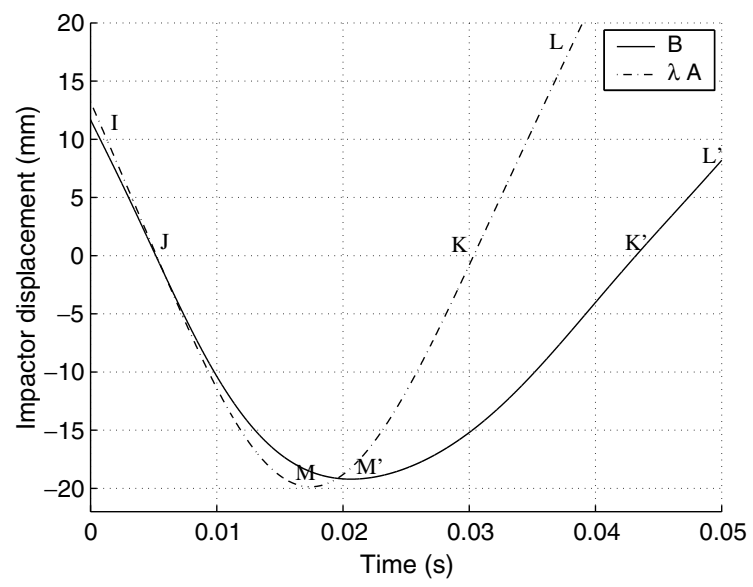

Fig. 12. Comparison between measured impactor displacement and similitude law result (vs time) at $V_{\text {init }}=2.2 \mathrm{~m} \mathrm{~s}^{-1}$.

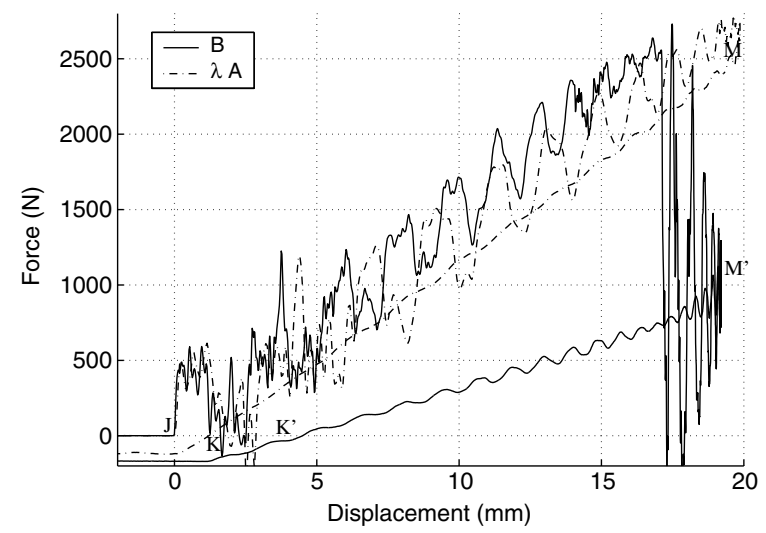

Fig. 13. Comparison between measured force and similitude law result (vs time) at $V_{\text {init }}=2.2 \mathrm{~m} \mathrm{~s}^{-1}$.

the contact force on the sample B falls brutally during delamination (point $\mathrm{M}^{\prime}$ ), whereas the calculated force $\lambda^{2} F$ increases to reach the value of $2772 \mathrm{~N}$ (point $\mathrm{M}$ ).

In conclusion, the similitude laws, developed in considering the elastic behavior of composite material, cannot be extended to describe the damaging behavior of a composite plate caused by impact. Thus, they do not allow to predict a sudden failure by delamination. In order to predict the complete behavior of a dynamically stressed composite structure (from the elastic response to the ruin of material), it is necessary to take into account the physical phenomena which interfere in the material degradation (delamination, fibre rupture...).

\section{Conclusion}

In order to validate similitude laws applied to composite structures, impact tests were performed on two laminated plate scales. Two impact velocities were chosen to evaluate structure behavior according to impact conditions (mass and velocity) and estimate the performances of the similitude laws to describe the behavior of a laminated composite structure at various scales. The lowest velocity $\left(V_{\text {init }}=1.8 \mathrm{~m} \mathrm{~s}^{-1}\right)$ was determined to reach high impact energy without generating damage visible with the naked eye. The velocity of $2.2 \mathrm{~m} \mathrm{~s}^{-1}$ was designed to reach a significant damage on at least one of the two scales. It has been thus possible to measure firstly the structure response according to their damage rate and secondly to estimate the relevance of the similitude laws in both cases (without or with damage). These tests show that usual similitude laws can be used 
to predict the elastic behavior of a scaled structure. However similitude laws, initially established to describe composite strucutre elastic behavior, can not be extended to take into account the structure damage during an impact. These results, completed by datas obtained on other composite structures (different in geometry) must allow to define new similitude laws taking into account the complete behavior of the composite material, from elastic response to damage phenomenon.

\section{References}

[1] Abrate S. Impact on composite structures. Cambridge University Press; 1998.

[2] Buckingham E. On physically similar systems; illustration of the use of dimensional equations. Phys Rev $1914 ; 4$.

[3] Qian Y, Swanson SR. An experimental study of scaling rules for impact damage in fiber composites. J Compos Mater 1990;24(May):559-70.

[4] Qian Y, Swanson SR. Experimental measurement of impact response in carbon/epoxy plates. AIAA J 1990;28(6):1069-74.

[5] Morton J. Scaling of impact-loaded carbon-fiber composites. AIAA J 1988;26(8):989-94.

[6] Nettles AT, Douglas MJ, Estes EE. Scaling effects in carbon/epoxy laminates under transverse quasi-static loading. Technical Report 209103, NASA, March; 1999.

[7] Dormegnie D, Coutellier D, Delsart D, Deletombe E, Ravalard Y. Analyse des effets d'échelles sur le comportement de structures composites. Mécanique et Ind 2003;4:7-15.

[8] Ungbhakorn V, Singhatanadgid P. Scaling law and physical similitude for buckling and vibration of antisymmetric angle-ply laminated cylindrical shells. Int J Struct Stability Dyn 2003;3(4):567-83.

[9] Rezaeepazhand J, Simitses GJ. Scale models for laminated cylindrical shells subjected to axial compression. Compos Struct 1996;34:371-9.

[10] Chouchaoui CS, Parks P, Ochoa OO. Similitude study for a laminated cylindrical tube under tensile torsion bending internal and external pressure part 2: scale models. Compos Struct 1999;44:231-6.

[11] Simitses GJ. Structural similitude for flat laminated surfaces. Compos Struct 2001;51:191-4.

[12] Rezaeepazhand J, Simitses GJ. Design of scaled down models for predicting shell vibration response. J Sound Vib 1996.

[13] Jackson KE. Workshop and scaling effects on composite materials and structures. Rapport NASA, Langley Research Center Hampton Virginia, NASA Conference Publication 3271; 1994.

[14] Ballere L, Viot P, Guillaumat L, Lataillade JL. Similitude laws evaluation for composites structures using optical techniques. In: The 2nd international conference in materials characterisation, Portland, USA; 2005. 